\title{
The Solvent Free Preparation of $\beta$-Amino Esters $\alpha, \beta$-Unsaturated Ketones and Esters with Domestic Microwave Oven
}

\author{
Mara E. F. Braibante, ${ }^{*}$ Hugo T. S. Braibante, Ademir F. Morel, Carla C. Costa and Marcelo G. Lima \\ Universidade Federal de Santa Maria, Departamento de Química, 97105-900 Santa Maria - RS, Brazil
}

\begin{abstract}
Uma série de cetonas e ésteres $\alpha, \beta$-insaturados $\beta$-amino ésteres, 4a-h e $\mathbf{6 a - d}$, derivados de $\alpha$-amino ácidos foi obtida a partir dos cloridratos dos $\alpha$-amino ésteres $\mathbf{2 a - d}$ e dos compostos 1,3-dicarbonílicos 3a,b e $\mathbf{5}$ em presença de trietilamina. Estes compostos foram preparados empregando energia de microondas, sem uso de solvente, utilizando como suporte sólido K-10 ou KSF e também foram efetuadas reações na ausência de suporte sólido.
\end{abstract}

A series of $\beta$-amino esters $\alpha, \beta$-unsaturated ketones and esters $\mathbf{4 a - h}$ and $\mathbf{6 a - d}$ derived from $\alpha$-amino acids have been prepared starting from $\alpha$-amino esters hydrochorides $\mathbf{2 a - d}$ with 1,3dicarbonyl compounds $\mathbf{3 a}, \mathbf{b}$ and $\mathbf{5}$ in presence of triethylamine. These compounds have been prepared under domestic microwave oven, under solvent free condition with and without solid support (K-10 or KSF).

Keywords: $\alpha$-amino acids, solid support, microwave, $\alpha$-amino esters

\section{Introduction}

We have recently investigated the use of microwave radiation in the preparation of $\beta$-enamino carbonylic compounds in reactions using solid support, K-10, under solventless conditions. ${ }^{1,2}$ The use of solventless conditions with heterogeneous media in domestic microwave ovens is an useful alternative and has received considerable attention due to its greater efficiency from an economic as well as an ecological point of view. ${ }^{3}$

Continuing our investigations exploring this methodology, we report herein the preparation of $\beta$-amino esters $\alpha, \beta$-unsaturated ketones and esters $4 \mathbf{a}-\mathbf{h}$ and $\mathbf{6 a - d}$. The $\beta$-enamino carbonylic compounds and the compounds described in this work are of interest as chemical intermediates for a variety of heterocyclic compounds with pharmacological properties, such as oxazolidinones, pyrrole and $\alpha$ - amino $-\beta$ lactams. ${ }^{4-9}$

In this work the $\beta$-amino esters $\alpha, \beta$-unsaturated ketones and esters $4 \mathbf{a}-\mathbf{h}$ and $\mathbf{6 a - d}$ were prepared by reaction of $\alpha$ amino esters $\mathbf{2 a - d}$ and 1,3-dicarbonyl compounds $\mathbf{3 a}, \mathbf{b}$ or 5 with microwave irradiation and organic solvent free condition using solid support, $\mathrm{K}-10$ or $\mathrm{KSF}$, in order to compare the acid characteristic of these supports. The use of potassium fluoride (KF), as an anionic support, with microwaves has been mentioned in the literature to prepare $\beta$-amino esters $\alpha, \beta$-unsaturated ketones trought the reaction only with $\alpha$-amino esters derivated of glycine, L-alanine, and L-proline and acetylacetone. ${ }^{10}$ We also tested these reactions without solid support.

\section{Results and Discussion}

The strategy used to obtain the compounds $\mathbf{4 a - h}$ and 6a-d, proceeded in a first step with the protection of the $\alpha$-amino acids. ${ }^{11}$ This protection was made necessary due to the prototropy observed between the carboxylic group and the amino group of the $\alpha$-amino acids. $\alpha$-amino esters hydrochlorides were prepared from $\alpha$-amino acid 1a-d glycine, L-alanine, L-serine and L-proline respectively in EtOH with thionyl chloride as catalyst, with these conditions the protected compounds $\mathbf{2 a - d}$ were isolated in excellent yield (Scheme 1).

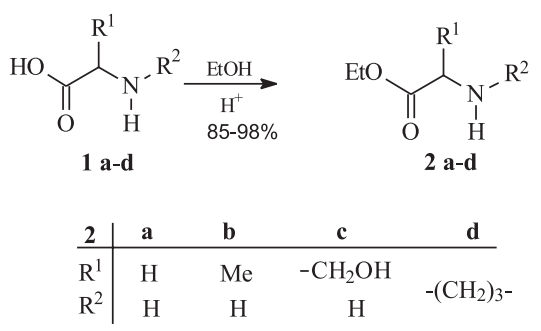

Scheme 1.

*e-mail: mara@quimica.ufsm.br 
Vol. 17, No. 1, 2006

The Solvent Free Preparation of $\beta$-Amino Esters $\alpha, \beta$-Unsaturated Ketones and Esters

185

For the preparation of $\beta$-amino esters $\alpha, \beta$-unsaturated ketones and esters $\mathbf{4 a}$-h we used the reaction of $\alpha$-amino esters $\mathbf{2 a - d}$ and acetylacetone $\mathbf{3 a}$ or ethyl acetoacetate $\mathbf{3 b}$ with 1 equiv. of triethylamine supported in K-10 or KSF with microwave irradiation without solvent, Scheme 2 . The compounds $\mathbf{4 a - h}$ were obtained in good yield (see Table 1).

Montmorillonite, especially K-10, has been used as an efficient acid catalyst in our laboratories to obtain $\beta$ enamino carbonylic compounds. ${ }^{12-14}$ The use of K-10 or KSF as solid support avoids the use of the organic acids that favour the formation of by-products or cause the hydrolysis of the enamino carbonylic compounds.

Due to the Brönsted acid nature K-10 or $\mathrm{KSF}^{15}$ and the possible interaction with polar compounds, we decided investigate these reactions without solid supports, using only microwave irradiation. We observed that $\mathbf{4 a - h}$ was obtained in excellent yield, Table 1 .

To evaluate if the acidic nature of the solid supports (K-10 or KSF) and the temperature could affect the optical purity of the chiral compounds that were obtained, we chose the compound $\mathbf{4 b}$, derivative of L-alanine. This compound was analyzed by GC (Gas Chromatography) with a chiral column and independent of the employed methodology (MW, MW/K-10 or MW/KSF), $95.7 \%$ of optical purity was obtained.

The good results obtained for the preparation of the acyclic $\beta$-amino esters $\alpha, \beta$-unsaturated ketones and esters 4a-h encouraged us to extend this methodology to obtain cyclic $\alpha, \beta$-unsaturated $\beta$-amino esters compounds with cis-s-cis configuration.

Table 1. $\beta$-amino esters $\alpha, \beta$-unsaturated Ketones and Esters 4a-h prepared

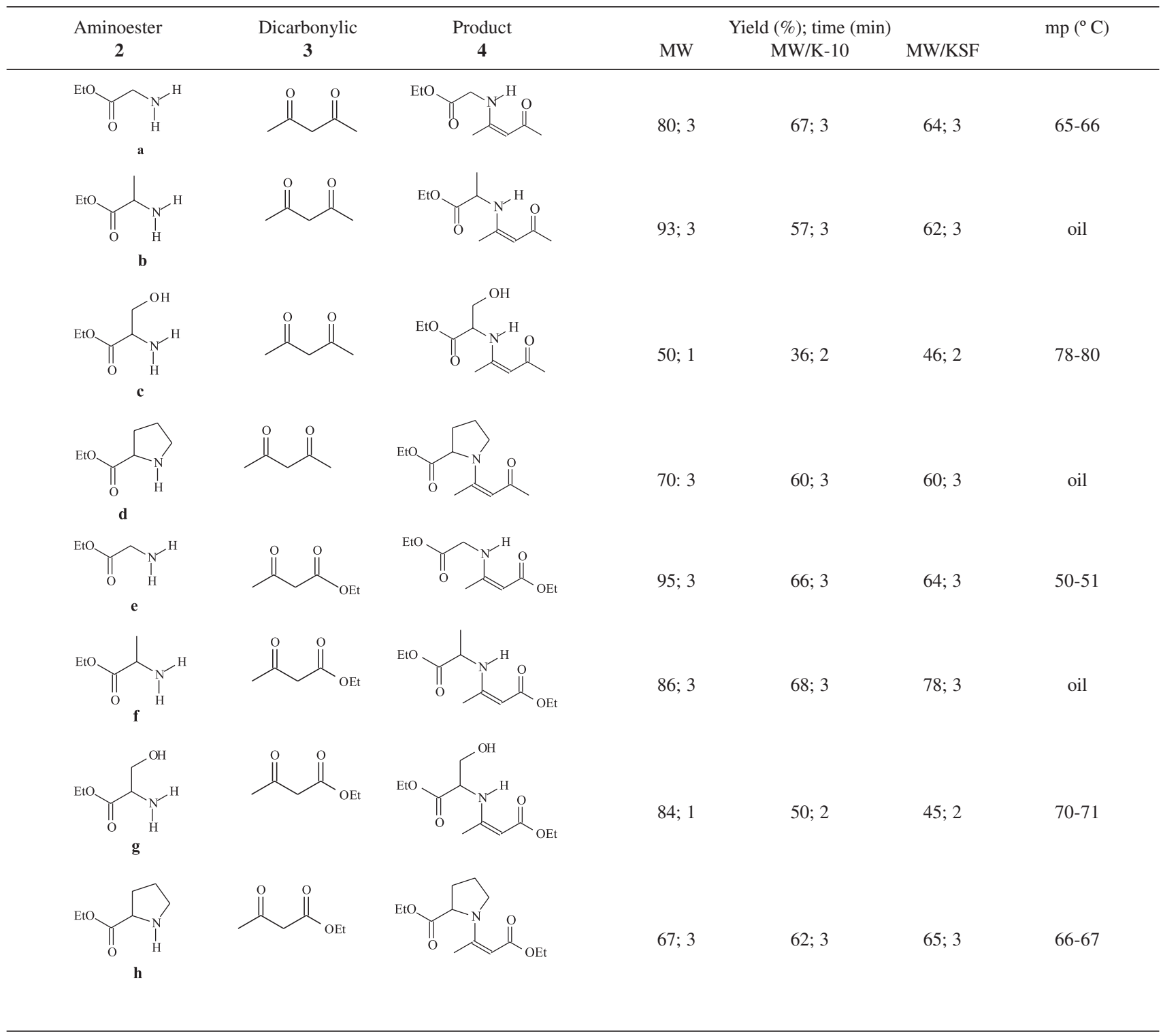




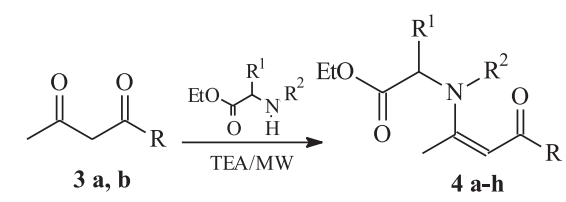

\begin{tabular}{c|cccccccc}
$\mathbf{4}$ & $\mathbf{a}$ & $\mathbf{b}$ & $\mathbf{c}$ & $\mathbf{d}$ & $\mathbf{e}$ & $\mathbf{f}$ & $\mathbf{g}$ & $\mathbf{h}$ \\
\hline $\mathrm{R}$ & $\mathrm{Me}$ & $\mathrm{Me}$ & $\mathrm{Me}$ & $\mathrm{Me}$ & $\mathrm{OEt}$ & $\mathrm{OEt}$ & $\mathrm{OEt}$ & $\mathrm{OEt}$ \\
$\mathrm{R}^{1}$ & $\mathrm{H}$ & $\mathrm{Me}$ & $-\mathrm{CH}_{2} \mathrm{OH}$ & & $\mathrm{H}$ & $\mathrm{Me}$ & $-\mathrm{CH}_{2} \mathrm{OH}$ & \\
$\mathrm{R}^{2}$ & $\mathrm{H}$ & $\mathrm{H}$ & $\mathrm{H}$ & $-\left(\mathrm{CH}_{2}\right)_{3}-$ & $\mathrm{H}$ & $\mathrm{H}$ & $\mathrm{H}$ & $-\left(\mathrm{CH}_{2}\right)_{3}-$
\end{tabular}

Scheme 2.

The ethyl-2-oxo-1-cyclopentanecarboxylate $\mathbf{5}$ used as dicarbonyl compound was obtained in agreement with the literature procedure, from diethyl adipate. ${ }^{16}$ The reaction occurs through Dieckmann cyclization, employing anhydrous aluminium trichloride and triethylamine in dichloromethane at room temperature.

Compounds 6a-d were obtained in excellent yield by reacting the dicarbonyl compound $\mathbf{5}$ dispersed on solid support (K-10 or KSF) with $\alpha$-amino esters hydrochloride 2a-d. These compounds were obtained in excellent yield with and without solid support (see Scheme 3 and Table 2). Triethylamine was used to reform the free amino ester and permit the attack of the nitrogen atom on the carbonyl group. When this reaction was performed without triethylamine the starting material was recovered. The structures of the products were unambiguously established based on the ${ }^{1} \mathrm{H}$ and ${ }^{13} \mathrm{C}$ NMR spectra experiments (Table 3).

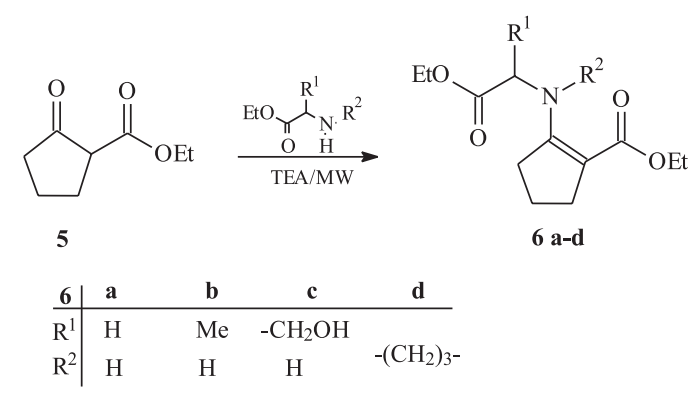

Scheme 3.

Table 2. $\beta$-amino esters $\alpha, \beta$-unsaturated Esters 6a-d prepared

(


Table 3. $\beta$-amino esters $\alpha, \beta$-unsaturated Ketones and Esters 4a-h and 6a-d prepared

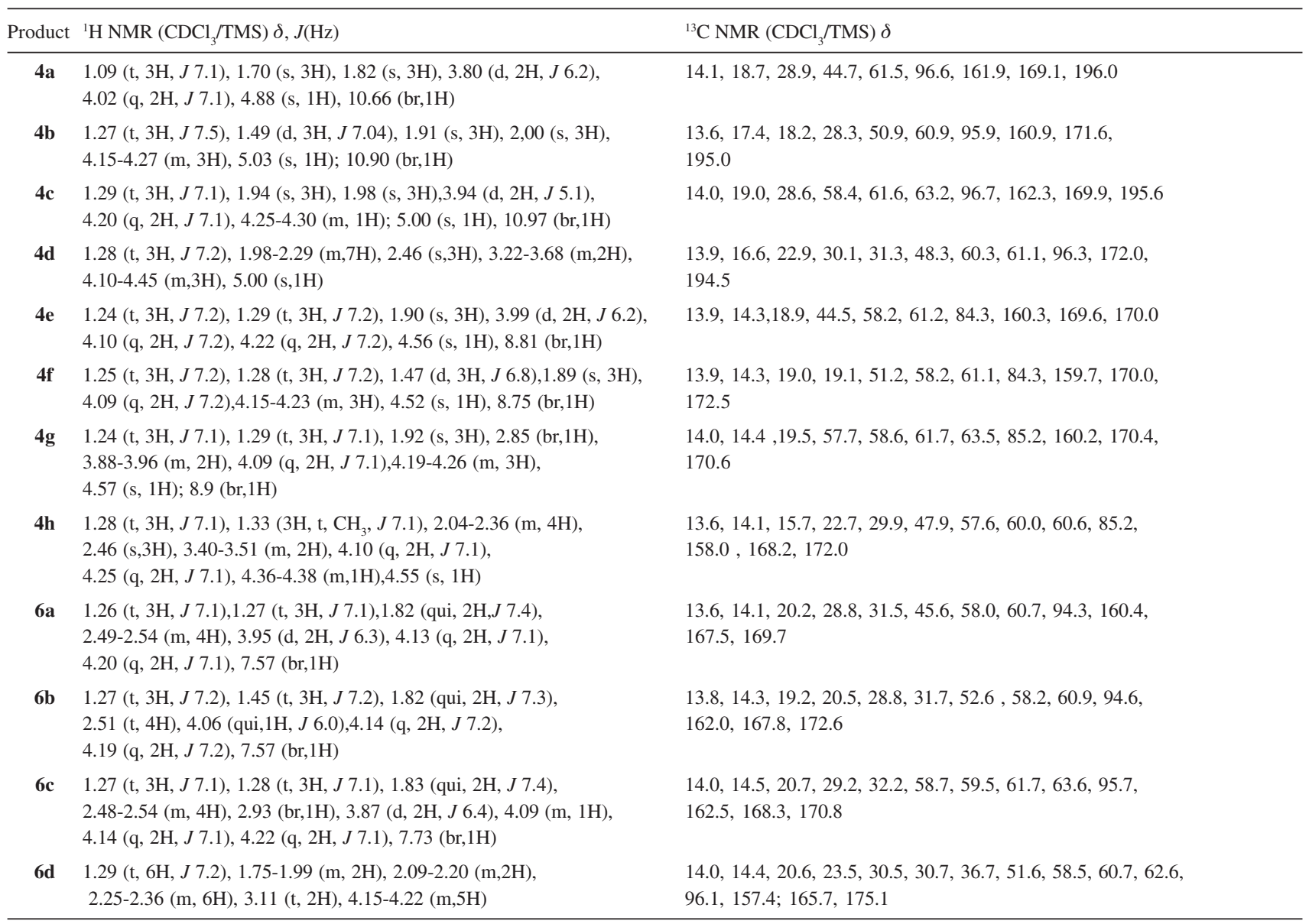

domestic MW with good to excellent yield. We believe that this procedure is an attractive addition to the existing methodologies to obtain synthons for asymmetric synthesis of heterocyclic compounds using cleaner methodologies with reduced time of reaction.

\section{Experimental}

Melting points were determined with a Microquímica APF-301 apparatus and are uncorrected. ${ }^{1} \mathrm{H}$ and ${ }^{13} \mathrm{C}$ NMR spectra were recorded on a Bruker DPX 200 spectrometer in deuteriochloroform/tetramethylsilane. Microwave irradiations were carried out in a SANYO EM-700T domestic oven $(700 \mathrm{~W})$. The solid support K-10 (Fluka) and KSF (Aldrich) were used. The temperature at the end of the experiment on the $\mathrm{MO}$ was between 70 and $80^{\circ} \mathrm{C}$ as determined by the melting points of compounds $4 \mathbf{c}$ and $\mathbf{4 g}$.

\section{$\alpha$-Amino esters $\mathbf{2 a} \boldsymbol{a}$. . General procedure}

To ethanol ( $100 \mathrm{~mL}$ ) previously cooled at $-20^{\circ} \mathrm{C}$, was added dropwise thionyl chloride ( $26 \mathrm{~mL} ; 35.6 \mathrm{mmol}$ ), after the $\alpha$-amino acid (100 mmol) was added, a suspension was observed. The reaction mixture was stirred at room temperature until not being observed the suspension. The solvent was evaporated in vacuum and the residue was dissolved in ethanol and precipitated with ethyl ether, the salt was collected by filtration and washed with ether to give the $\alpha$-amino esters hydrochlorides $\mathbf{2 a - c}$ solids, except for $\mathbf{2 d}$ which is oil.

\section{Typical procedure with $\mathrm{K}-10$ or KSF}

Acetylacetone $\mathbf{3 a}$ or ethyl acetoacetate $\mathbf{3 b}$ or ethyl cyclopentanecarboxylate $5(5 \mathrm{mmol})$ and $\alpha$-amino esters 2 a-d $(7.5 \mathrm{mmol}$ to obtain 4 and $10 \mathrm{mmol}$ for 6 were used) with 1 equiv. of triethylamine were dispersed on $\mathrm{K}-10$ or KSF $(1.5 \mathrm{~g})$. The heterogeneous mixture was submitted to microwave irradiation at $155 \mathrm{~W}$ for the time described in Table1 and Table 2. The products were extracted by washing the K-10 or KSF with ethyl acetate. The organic layer was washed with water, dried with $\mathrm{MgSO}_{4}$, filtered and the solvent was removed under vacuum to give $4 \mathbf{a}-\mathbf{h}$ and $\mathbf{6 a - d}$. 


\section{Typical procedure without $\mathrm{K}-10$ or $\mathrm{KSF}$}

Acetylacetone $\mathbf{3 a}$ or ethyl acetoacetate $\mathbf{3 b}$ or ethyl cyclopentanecarboxylate $5(5 \mathrm{mmol})$ and $\alpha$-amino esters 2a-d (7.5 mmol to obtain 4 and $10 \mathrm{mmol}$ for 6 were used) with 1 equiv. triethylamine were submitted to microwave irradiation for 1-3 min. (see Table 1 e Table 2) at $155 \mathrm{~W}$. After the reaction mixture was cooled at room temperature and was added ethyl acetate. The organic layer was washed with water, dried with $\mathrm{MgSO}_{4}$, filtered and the solvent was removed under vacuum to give $\mathbf{4 a - h}$ and $\mathbf{6 a - d}$.

\section{Acknowledgments}

We are grateful to the Coordenação de Aperfeiçoamento de Pessoal de Nível Superior (CAPES), Brazil and Fundação de Amparo a Pesquisa do Estado do Rio Grande do Sul (FAPERGS) fellowships to C.C.C and M. G. L respectively. We thank Dr. Robert Burrow for helpful comments on the manuscript.

\section{References}

1. Braibante, H. S.; Braibante, M. E. F.; Rosso, G.B.; Oriques, D.A.; J. Braz. Chem. Soc. 2003, 14, 994 (available free of charge at http://jbcs.sbq.org.br).

2. Braibante, M. E. F.; Braibante, H. S.; Rosso, G.B.; Roza, J.K.; Synthesis 2001, 1935.
3. Lidström, P.; Tierney, J.; Wathey, B.; Westman, J.; Tetrahedron 2001, 57, 9225.

4. Kascheres, C.M.; J. Braz. Chem. Soc. 2003, 14, 945(available free of charge at http://jbcs.sbq.org.br).

5. Negri, G.; Kascheres, C.; Kascheres, A. J.; J. Heterocycl. Chem. 2004, 41, 461.

6. Ferraz, H. M. C.; Pereira, F. L. C.; Quim. Nova 2004, 27, 89.

7. Gupta, S. K.; Synthesis 1975, 724.

8. Hombrecher, H. K.; Horter, G.; Synthesis 1990, 389.

9. Sharma, S.D.; Gupta, P.K.; Tetrahedron Lett. 1978, 46, 4587.

10. Rechsteiner, B.; Texier-Boullet, F.; Hamelin, J.; Tetrahedron Lett. 1993, 34, 5071.

11. Brenner, M.; Huber, W.; Helv. Chim. Acta 1953, 36, 1109.

12. Braibante, M. E. F.; Braibante, H. S.; Valduga, C. J.; Squizani, A.; Synthesis 1998, 1019.

13. Braibante, M. E. F.; Braibante, H. S.; Salvatore, S. J. S. A.; Quim. Nova 1990, 13, 67.

14. Braibante, M. E. F.; Braibante, H. S.; Missio, L.; Andricopulo, A.; Synthesis 1994, 898.

15. Laszlo, P.; Preparative Chemistry Using Supported Reagents, Academic Press: New York, 1987.

16. Peçanha, E. P.; Barreiro, E. J.; Fraga, C. A. M.; Quim. Nova 1997, 20, 435.

Received: July 26, 2005

Published on the web: January 18, 2006 